\title{
We are in 'the breakout room'. Now what? An e-portfolio study of virtual team processes involving undergraduate online learners
}

Murod Ismailov, University of Tsukuba (Corresponding author)

Joel Laurier, University of Tsukuba

\begin{abstract}
The COVID-19 pandemic, resulting in unprecedented campus closures and social distancing, has reinforced the value of learning using a virtual teamwork format. While a large body of research focuses on the inputs (members' skills, motivation, technology, virtuality) and outcomes (satisfaction, performance, learning) of virtual teamwork, to date, only a limited number of studies have explored virtual teamwork processes involving university students. By drawing on the team processes model (Marks et al., 2001), in this qualitative study, we extend the scope of virtual team processes to a university online course. In addition, we explore transition, action, and interpersonal processes that undergraduate students experience when learning in virtual teams. The study participants included Japanese and international students $(\mathrm{N}=20)$ from three universities in Japan taking a synchronous online course in International organisations during the summer of 2020; 15 combinations of virtual teams were created. The study is based on the inductive content analysis of e-portfolios created and managed by students taking the online course. The findings show that virtual teams are multitasking entities that transition through multiple processes simultaneously and consequentially to achieve team goals. From the analysed e-portfolios, it can be observed that across all themes, systems monitoring (action processes), affect management (interpersonal processes), and strategy formulation and planning (transition processes) have been crucial in invigorating virtual teams toward task accomplishment. Finally, the study discusses both theoretical and practical implications.
\end{abstract}

\section{Keywords}

Team processes, virtual teams, e-portfolio, online learning, undergraduate students, Japan.

\section{Introduction}


One of the main goals of higher education, particularly in today's highly interconnected and digitized world, is to prepare students for working collaboratively across cultural, geographic, and organizational boundaries (Page et al., 2020). Hence, teamwork is becoming an important element of undergraduate education, providing students with the opportunity to acquire essential skills. Because learning in teams fosters positive interdependence and responsibility, improves intrinsic motivation to learn, and encourages greater awareness, autonomy, and control of the learning processes, such practices are highly valued among students (HerreraPavo, 2021; Authors, 2021). Researchers have addressed universities' needs to create a new generation of on-campus/virtual learning environments to support the shift toward more student-centred and team-based collaborative learning (e.g., Bravo et al., 2016; Jamieson et al., 2008).

Previous research has extensively addressed teamwork in a conventional face-to-face environment involving college students (Hansen, 2006). These studies focus on various dynamics related to student teams, such as team cohesiveness (Bravo et al., 2019), teamwork outcomes, goal attainment and learning satisfaction (Bravo et al.; Pineda \& Lerner, 2006), teamwork experiences (Wilson et al., 2018), and performance measurement and assessment (Britton et al., 2017). Compared to on-campus collaborative learning, virtual collaborative learning is more demanding for students as the virtual context involves different tools and methods of communication and collaboration (Kopp et al., 2012).

The COVID-19 pandemic, resulting in unprecedented campus closures and social distancing, has reinforced the value of virtual collaborative learning and teamwork. These developments have also challenged the status quo dominated by traditional didactic learning, face-to-face 
lectures, and chalk talks (Almarzooq et al., 2020). Most recent studies suggest that the experience of social distancing and remote learning might have lasting implications on future university programme designs, and the real value of learning will be in the quality of interaction, practical collaborative work, and engagement in online and in-person learning (Beech \& Anseel, 2020).

Collaborative learning among students can take place in various online settings using learning communities, wikis, blogs, discussion prompts, and other virtual taskwork, where students are assigned to a group to share their experiences or engage in the course material with each other (Page et al., 2020; Verstegen et al., 2018). However, studies suggest that virtual teamwork is different from conventional collaborative online learning in that the former involves teams required to perform clear task(s), interdependent members, and shared outcomes. Additionally, electronically communicating with other members does not transform a group of students into a virtual team (Gibson \& Cohen, 2003; Page et al., 2020).

To date, research on teamwork has showed the prevalence of the Input-Process-Outcome (I-PO) model (McGrath, 1984) widely applied by researchers to analyse virtual team membership, members' knowledge and skills, motivation, conflict, teamwork satisfaction and productivity (Martins et al., 2004). Although the initial research of teamwork tended to focus more on the question of what makes teams effective (i.e. the team members' knowledge/talent, group size, use of specific technology), recently, studies have begun to broaden their focus to include not only team inputs and outcomes, but also emphasize the role of processes and other mediating factors that affect team performance. This shift has allowed new insights when addressing the question of why teams are effective (Ilgen et al., 2005; Martins et al., 2004). For example, a meta-analytic study by LePine et al. (2008) suggested that teamwork processes have positive 
relationships with team performance and member satisfaction, and the relationships are similar across different dimensions of teamwork processes developed by Marks et al. (2001).

While there is growing interest and value, especially during the COVID-19 pandemic, in understanding the virtual taskwork for coursework-based collaborative learning and project management (Herrera-Pavo, 2021; Hu, 2009; Page et al., 2020; Yoon \& Johnson, 2008), few studies have looked into transition, action, and interpersonal processes during virtual teamwork in an undergraduate online learning context. Additionally, the relationships between these three processes in a university learning context have not yet been addressed. In this study, we posit that virtual teamwork processes involving university students should be thoroughly investigated, especially as new technologies for collaboration are constantly being developed and used in higher education (Abarca et al., 2020).

In this qualitative study, we draw on the team processes model (Marks et al., 2001) and extend the scope of virtual team processes to the university online learning context by exploring various dynamics and processes experienced by students when working in virtual teams. To understand virtual team functioning, it is important to study how certain conditions influence distinct kinds of processes, which in turn could lead to and influence other independent outcomes (Holtz et al., 2020). Qualitatively examining team processes through the prism of personal experiences, phenomena, and context in educational research is necessary to give us a deeper understanding of the hows and whys of student interaction during virtual teamwork.

In the following section we will review the literature on virtual teamwork to explore its definitions, key attributes, as well as the input-process-outcome (I-P-O) framework. This will be followed by the sections outlining the aim of study, theoretical assumptions, research 
questions and the methodology. After presenting the results, the paper will discuss the theoretical and pedagogic implications of the study. The paper will conclude by outlining its limitations and areas of future research.

\section{Literature review}

\section{Virtual teamwork: definitions and key attributes}

The early definitions of a virtual team were developed in contrast with a conventional face-toface team whose members typically work together in close physical proximity and regularly coordinate their activities through in-person meetings (Guzzo \& Dickson, 1996). The focus on the dichotomy of virtual versus face-to-face teams has been influenced by the existence of hybrid teams that met and worked together in both face-to-face and virtual environments (Nunamaker et al., 1998). Based on the newer studies, Martins et al. (2004) pointed to a tendency in many studies to define virtual teams in relation to their 'virtualness' as one of the key characteristics. For example, studies suggest that teams need to be considered along the boundaries of virtualness based on the amount of time members spend working together as well as the level of technology mediating their teamwork (Griffith \& Neale, 2001). In other words, when it comes to the extent of virtualness required, studies seem to suggest that it may vary depending on the complexity of the virtual task performed (Bell \& Kozlowski, 2002), the structures and capabilities provided by the technology (Griffith \& Neale, 2001), as well as members' skills and capabilities (Martins et al., 2004).

Despite ongoing debates about the degree of virtualness needed in creating virtual teams, many researchers agree that these teams are functional units whose members meet and work using technology as their primary medium of communication to achieve shared goals (Bell \& Kozlowski, 2002; Griffith \& Neale, 2001; Lurey \& Raisinghani, 2001). For instance, one group 
of researchers (Hertel et al., 2005:71) has described virtual teams as 'two or more persons who collaborate interactively to achieve common goals, while at least one of the team members works at a different location, organization, or at a different time, so that communication and coordination is predominantly based on electronic communication media'. By examining both traditional and newer conceptualizations, Martins et al. (2004: 808) defined virtual teams as 'teams whose members use technology to varying degrees in working across locational, temporal, and relational boundaries to accomplish an interdependent task'. Indeed, many studies attempting to define the term, have mentioned at least three of the following characteristics of a virtual team:

\section{Geographic dispersion}

Compared with conventional face-to-face teams, members of virtual teams are not constrained to the same geographic location and can be located anywhere in the world (Montoya-Weiss et al., 2001; Odenwald, 1996). Members of a virtual team may belong to the same organization but physically dispersed across different geographic locations or may be affiliated with different organisations and work at the same geographic location (Martins et al., 2004; Maznevski \& Chudoba, 2000). The possibility for individuals worldwide to work together on the same project without physically being at the same location has implications on both efficiency and effectiveness of the group work (Gibson \& Cohen, 2003).

\section{The use of technology}

Virtual teams often have no choice but to communicate electronically to perform their tasks and effectively coordinate their activities (Gibson \& Cohen, 2003). Therefore, teams whose 
members are dispersed across different locations must choose optimal technology to replace in-person interaction (Martins et al., 2004). They may use various communication technologies that range in media richness and sophistication (Daft \& Lengel, 1984; Workman et al., 2003) and in the degree to which they enable real-time versus asynchronous teamwork (Riopelle et al., 2003). With advancement of the Web 2.0 technologies (Guth \& Helm, 2010), more virtual collaboration is expected to occur using multimedia-rich tools, such as videoconferencing, video-chats, and real-time project management/collaboration apps compared with conventional fax, telephone, and emails which are lower in media richness and synchronicity (Klitmøller \& Lauring, 2013). Additionally, researchers suggest that because all teams use technology, the use of technology in itself does not characterize the virtualness of a team. However, the extent to which a team uses and relies on electronic communication may influence its degree of virtualness (Bell \& Kozlowski, 2002; Gibson \& Cohen, 2003).

\section{Organizational diversity}

Virtual teams are likely to include members from multiple disciplines, functions, organizations, countries, and cultures, or to consist of members from the same profession, organization, and culture (Gibson \& Cohen, 2003; Maznevski \& Chudoba, 2000). The greater the geographic distance between the virtual team members and their organizational diversity, the higher the likelihood that the team will include members from different professional, cultural, and sociolinguistic backgrounds (Chudoba et al., 2005; Bergiel et al., 2008). Like the degree of virtuality, the existence of differences increases the complexity of a virtual teamwork (Gibson \& Cohen, 2003). According to Shapiro et al. (2002) it is typical for the virtual team members to work across diverse competences, skills, assumptions, and motivations. 


\section{Task interdependence and shared outcomes}

Being geographically distant, using communication technology, and working at different organisations does not make a group of individuals a team. Any team, including a virtual team, needs to have a solid task to perform and consist of interdependent members with shared responsibilities and outcomes (Hertel et al., 2005). Task interdependence occurs when the members of a virtual team need to coordinate their activities regularly so that the input from one member significantly affects the output of other team members (Thompson, 1967). Studies suggest that the higher the level of goal, task, and outcome interdependence, the greater the degree of a team's motivation, communication, cohesion, and overall teamwork effectiveness (Bouas \& Arrow, 1996; Hertel et al., 2004).

\section{The I-P-O framework of virtual teamwork}

Previous research on virtual teamwork suggests that virtual teams are complex social entities, and many factors work together to determine their functionality and effectiveness (Gibson \& Cohen, 2003). The prevailing framework often mentioned in the studies of virtual teams is referred to as input-process-outcome (I-P-O) model (Martins et al., 2004; McGrath, 1984).

Inputs. According to the I-P-O framework, inputs represent the physical and organisational characteristics of a team, including member 'knowledge, skills, abilities, and other characteristics' known as KSAOs (Krumm et al., 2016), apart from team size, the nature of task performed, the type of communication technology used, and whether the members have prior collaborative work experience (Kirkman et al., 2004; Leenders et al., 2003). Blackburn et al. (2003) suggested that the unique challenges of working virtually require that team members have a broader set of competencies, including self-management, virtual 
communication, cultural sensitivity, trust building, and skills in using technology. Some studies also suggested that inputs in the form of KSAOs are more relevant for individual team members' and the team's success in virtual teamwork than in traditional teamwork (Krumm et al., 2016).

Processes. Team processes are defined as members' interdependent acts that convert inputs to outcomes through cognitive, verbal, and behavioural, activities directed toward organizing taskwork to achieve collective goals and are inclusive of three distinct processes: (1) transition, (2) action, and (3) interpersonal processes (Marks et al., 2001: 357). In the transition processes, teams formulate their mission, specify goals, and create strategies to achieve these goals (Brannick et al., 1997; Dickinson \& McIntyre, 1997; Prince \& Salas, 1993; Stout et al., 1999). Empirical studies have found that embedded goal-setting structure helped virtual teams achieve stronger collaboration, better team cohesion and commitment, better perceived decision quality, and more decision alternatives compared with virtual teams without goal-setting structures (Huang et al., 2003). Researchers also argued that effective virtual teams tend to establish a set of rules that help team members communicate and collaborate productively (Blackburn et al., 2003).

Action processes, on the other hand, can be characterized by the degree of coordination, communication, and support among team members, as well as monitoring team's resources and performance (Dickinson \& McIntyre, 1997; Jentsch et al., 1999; Zalesny et al., 1995). Studies looking into virtual team processes tend to emphasize coordination and communication (Martins et al., 2004), whereas dynamics of engagement, mutual support, and progress monitoring are less frequently addressed in the literature (Cannon-Bowers \& Bowers, 2011; Costa et al., 2014).

Interpersonal processes encompass conflict management, affection motivation, confidence building, and other processes that govern human relationships inside a team (Cannon-Bowers 
et al., 1995; Varela \& Mead, 2018; Simons et al., 1999; Simons \& Peterson, 2000; Smolek et al., 1999). These relationships play an important role in strengthening the team's morale, motivation, trust, and sense of belonging (Blackburn et al., 2003). Some researchers argued that interpersonal processes underlie both the transition and action phase processes (Fisher, 2014). Studies focusing on students' teamwork specifically found that perceptions of improvement in skills and learning, as well as the development of a more positive attitude toward teamwork occur within interpersonal processes (Bravo et al., 2016; Pineda \& Lerner, 2006).

Outcomes. Outcomes refer to the end-results of teamwork which can be directly related to the tasks performed (e.g. goal achievement, productivity, timeliness, learning, and innovation), or unrelated to the task, such as commitment, satisfaction, and stronger networking (Gibson \& Cohen, 2003). Studies examining the effectiveness of virtual teamwork tend to distinguish between affective and performance outcomes (Martins et al., 2004). Studies report that even though the affective outcomes (e.g., task satisfaction, goal attainment, etc.) in virtual teams are usually less positive compared with face-to-face teams (Baltes et al., 2002), this effect might decline once team members adapt to the virtual working environment (Hertel et al., 2005). As for the task performance outcomes, studies have found that in the virtual teamwork environment it takes more time to make effective decisions compared with face-to-face environment (Cappel \& Windsor 2000; Graetz et al., 1998).

Overall, one can posit that virtual teamwork and relationships among its dimensions were extensively studied from the business and organizational perspectives. In addition, as it was mentioned in the introduction, there is a plethora of studies focusing on virtual collaborative learning and teamwork in the higher educational context, notably in pre-COVID period. However, to date, few studies have focused on the process-oriented dynamics of virtual teamwork in a multi-university setting involving undergraduate students from diverse 
professional backgrounds. In this study, we will attempt to address some of these gaps in the literature.

\section{The aim, theoretical framework, and research questions}

By thematically synthesizing and examining the perceptions of students regarding their virtual teamwork participation, this study aims to map out the occurring team processes along transition, action, and interpersonal dimensions. Following the team processes model developed by Marks et al. (2001), this study builds on the assumption that virtual teamwork is based on a multiphase and an episodic interaction among team members working together to accomplish a concrete goal yielding shared outcome. In other words, we expect that virtual teams in our experiment will act as 'multitasking units that perform multiple processes simultaneously and sequentially to orchestrate goal-directed taskwork' (Marks et al., 2001: 356). In their team processes model supported by an extensive meta-analytic work, Marks and her co-investigators have outlined and defined three main phases, and later divided them further into process dimensions. For illustration purposes, we have created virtual team processes diagram by adopting the original definitions (see Fig 1). 


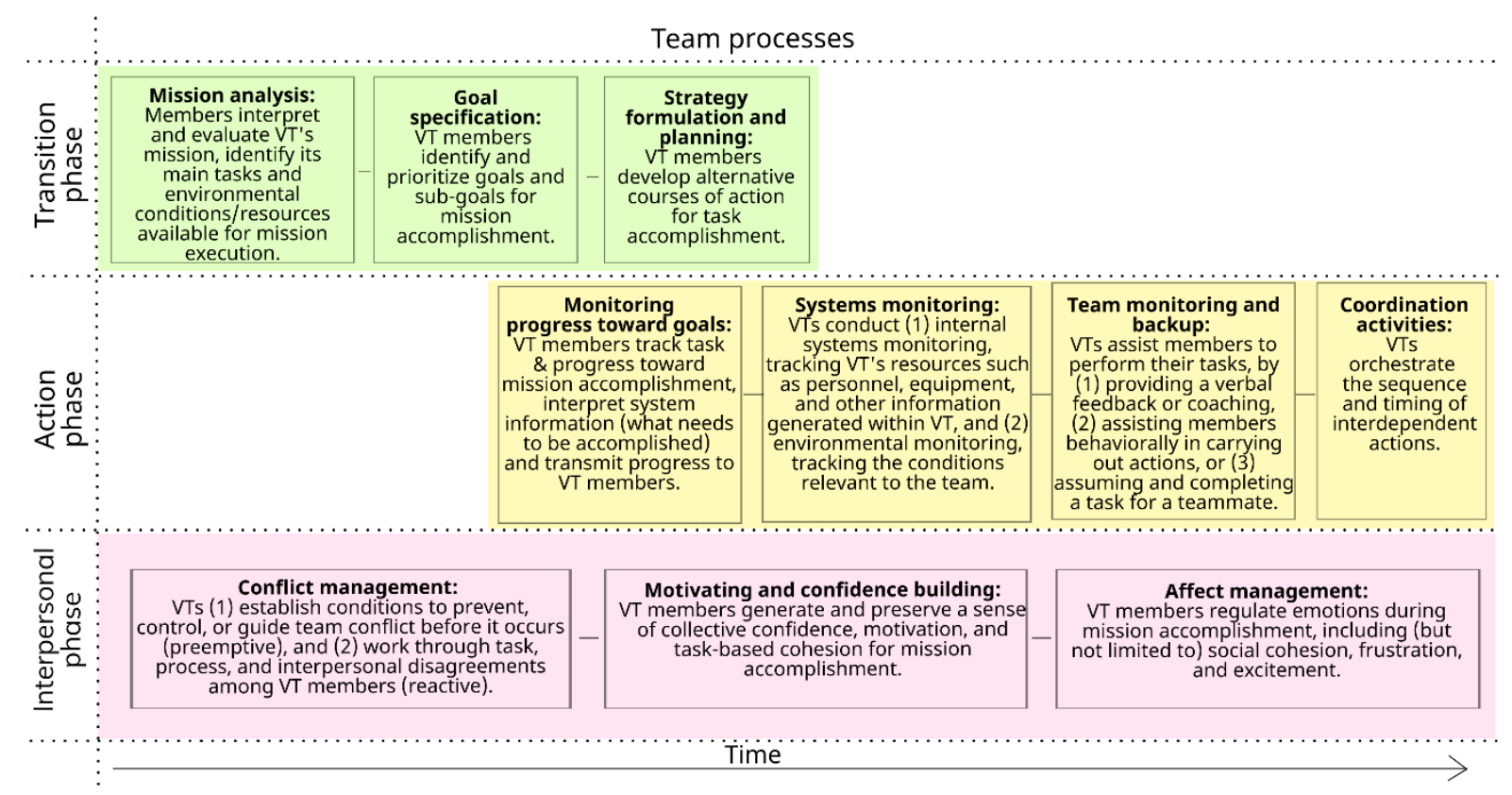

Figure 1. The taxonomy of team processes (adapted from Marks et al. 2001)

We posit that virtual teams composed of undergraduate students enrolled in a multi-university synchronous online course during their work on assigned tasks will likely go through similar team processes as any other virtual team. In doing so, each virtual team might attempt to accomplish the team's main goal by transitioning from one phase to another, though the work rhythms may vary from team to team. According to the adopted model, we expect that virtual teams in our study should be able to pass through all three main phases during their work on a task (Marks et al., 2001: 364-369), as follows:

1. During the transition phases virtual teams of students would be engaged in evaluation and planning activities to guide their task execution. At this time, students would likely focus on their team's mission analysis, by specifying the goals, and formulating their strategy and planning their further steps (Brannick et al., 1997; Dickinson \& McIntyre, 1997; Prince \& Salas, 1993; Stout et al., 1999).

2. During the action phases student teams might conduct activities to accelerate goal attainment. Students, individually or as a team, are expected to closely monitor progress 
toward their team's goal, their resources, and members' performance, and initiate backup responses and coordination activities (Dickinson \& McIntyre, 1997; Jentsch et al., 1999; Zalesny et al., 1995).

3. As part of the interpersonal phases, students are expected to deal with potential conflicts, motivation, and confidence building, as well as affect management. Following the original model, we expect that interpersonal processes will occur throughout transition and action phases and will play a critical role for ensuring the effectiveness of other two processes (Cannon-Bowers et al., 1995; Varela \& Mead, 2018; Simons et al., 1999; Simons \& Peterson, 2000; Smolek et al., 1999).

To address these theoretical assumptions, in this study we pose the following research questions:

RQ1. What are the process-related attributes of virtual teamwork in a multi-university online learning environment?

RQ2. How do team processes evolve temporally across different virtual teams and tasks?

\section{Methods}

The study uses a systematic and inductive content analysis of students' e-portfolios to examine their experiences of working in at least 3 of the 15 established virtual teams. This qualitative approach allows an in-depth and real-time observation of processes emanating from the recordings of student perceptions. Because 'virtual worlds are multi-user in nature and they exist as shared social environments with synchronous communication and interaction' (Boellstorff et al., 2012: 7), systematic content analysis helps to explore both micro and macro 
dynamics of online media practice and to uncover new or divergent themes across virtual team interactions (Hjorth et al., 2017).

\section{Participants}

This study adopted a convenience sampling method. The participants in this study were 20 undergraduate students enrolled in a multi-university online course in 'International organizations' taught in AY2020. This course is an elective course and is open to all undergraduate and graduate students from year one upward. This academic course is part of the curriculum of a major humanities-oriented university (University A) in the greater Tokyo area. According to the inter-university agreement, University A has pledged to support universities that have limited capability to offer English-medium instruction courses in social sciences and humanities. Thus, University A has opened its courses to the students of the two technical universities located in the same area (University B and University C). 14 out of 20 students (70\%) belonged to University A, whereas 5 students (25\%) belonged to University B, and 1 student (5\%) was from University C. The cohort consisted of 14 females $(70 \%)$ and 6 males $(30 \%)$. The participants' ages ranged from 19 to 23 years $(M=20.4, S D=1.3) .17$ students $(85 \%)$ were Japanese, and 3 participants were international students from Northern Europe, South-East Asia, and East Asia.

The main reason for recruiting students from different years and majors was to replicate the conditions of a real-life virtual teamwork in which participants typically have differences in terms of age, experience, and professional background. The disadvantage of this approach may be that some participants (e.g., freshmen) would be discouraged to work with their more experienced classmates (e.g., sophomores). Nonetheless, one of the aims of this study is to explore both the challenges and benefits of virtual team processes in an e-learning environment. 
During the pre-course survey using an anonymous real-time presentation application (Mentimeter $\left.{ }^{\mathrm{TM}}\right), 9$ students $(45 \%)$ indicated that they had never worked in a non-virtual (faceto-face) teamwork setting, whereas 8 students (40\%) had experienced face-to-face work at least twice or more. As for virtual teamwork experience, 17 students $(85 \%)$ indicated that they had never participated in virtual teamwork before, whereas all students $(100 \%)$ reported that they had never studied or worked on a project with virtual teams consisting of students from other institutions.

During a three-day intensive online course, the students had worked on three unique virtual assignments (See Fig 4). Each task required a reshuffling so that each team would be markedly different from the others for the purpose of analysis. Every participant was assigned to at least three unique teams over the duration of the online course. This procedure resulted in 15 combinations of virtual teams with 4 members in each team whose demographic and professional characteristics, in terms of gender, age, academic major, as well as basic conceptual knowledge and familiarity with the live-streaming technology were comparable. Alexander (2006) suggested that team size contributes to effective communication, and that the optimal size for virtual teams is between 4 and 7 members. By creating many team combinations, the researchers aimed to create diverse conditions to explore virtual team processes. Demographic information is presented in Table 1. Additional information on the demographic composition of virtual teams can be found in Appendix 1.

Field of study Total Fem Male 1styear 2ndyear 3rdyear 4th year Jap Int

\begin{tabular}{lccccccccc}
\hline Int/Area & 10 & 8 & 2 & 6 & 2 & 2 & 0 & 10 & 0 \\
Lang/Cul & 4 & 3 & 1 & 2 & 0 & 1 & 1 & 2 & 2 \\
Jap & 1 & 1 & 0 & 0 & 1 & 0 & 0 & 0 & 1 \\
Inf/Eng & 1 & 0 & 1 & 1 & 0 & 0 & 0 & 1 & 0
\end{tabular}




\begin{tabular}{lccccccccc} 
Bio/life & 2 & 0 & 2 & 1 & 1 & 0 & 0 & 2 & 0 \\
Env/Nat & 2 & 2 & 0 & 1 & 1 & 0 & 0 & 2 & 0 \\
\hline Total & $\mathbf{2 0}$ & $\mathbf{1 4}$ & $\mathbf{6}$ & $\mathbf{1 1}$ & $\mathbf{5}$ & $\mathbf{3}$ & $\mathbf{1}$ & $\mathbf{1 7}$ & $\mathbf{3}$
\end{tabular}

Key: Int/Area = International and Areas studies; Lang/Cul = Language and Culture studies; Jap = Japanese studies; Inf/Eng = Informatics and Engineering; Bio/Life = Biotechnology and Life sciences; Env/Nat = Environmental and natural resources sciences; Total $=$ Total number of students; Fem = female; Jap = Japanese (local) students; Int $=$ International students.

Table 1. Demographic information on student of participants

\section{Course content and team assignments}

The academic course titled 'Japan in International Organizations' is a two-credit elective undergraduate course aimed at equipping students with conceptual knowledge of international and regional cooperation involving Japan, as well as practical skills of collaboration, negotiation, problem-solving, and decision making. The medium of instruction of the course was English. Prior knowledge of political concepts was not set as prerequisite. The course consisted of 15 intensive modules lasting 90 minutes each carried out over the three consecutive days. All lectures, presentations, and team assignments were carried out synchronously using Zoom ${ }^{\mathrm{TM}}$ application. Along with a few individual tasks, the main coursework (80\%) consisted of three virtual team assignments (see Appendix 2).

\section{Data collection}

The primary data were collected through observation and analysis of e-portfolios created by students during the course using shared Google Docs files. E-portfolio is a personal digital record that contains evidence about one's accomplishments in the form of artefacts and 
reflection on learning (Balaban et al., 2013). Unlike an e-diary that typically contains personal memos and private remarks on certain experiences, e-portfolios can sometimes be accessed for viewing by selected individuals since they display and guide team discussions about members' learning experiences. Studies report the effectiveness of e-portfolios for metacognitive activities such as planning, and organizing, monitoring, and regulating collaborative learning because they provide opportunities for process assessment, self-assessment, and co-evaluation (Balaban et al., 2013; Herrera-Pavo, 2011). Because only a few participants were familiar with e-portfolio method, the instructor created guidelines which included eight guiding prompts and detailed descriptions (See Appendix 3). Following every team activity, students were requested to spend 20 minutes to add a comment into their e-portfolio. All student e-portfolios were in the course's Google Drive folder and could be freely accessed by participants.

By signing and submitting a consent form, all students gave their permission for using their virtual teamwork e-portfolios as primary data for this research. To protect students' personal information and privacy, pseudonyms were used when presenting the results of content analysis.

\section{Data analysis}

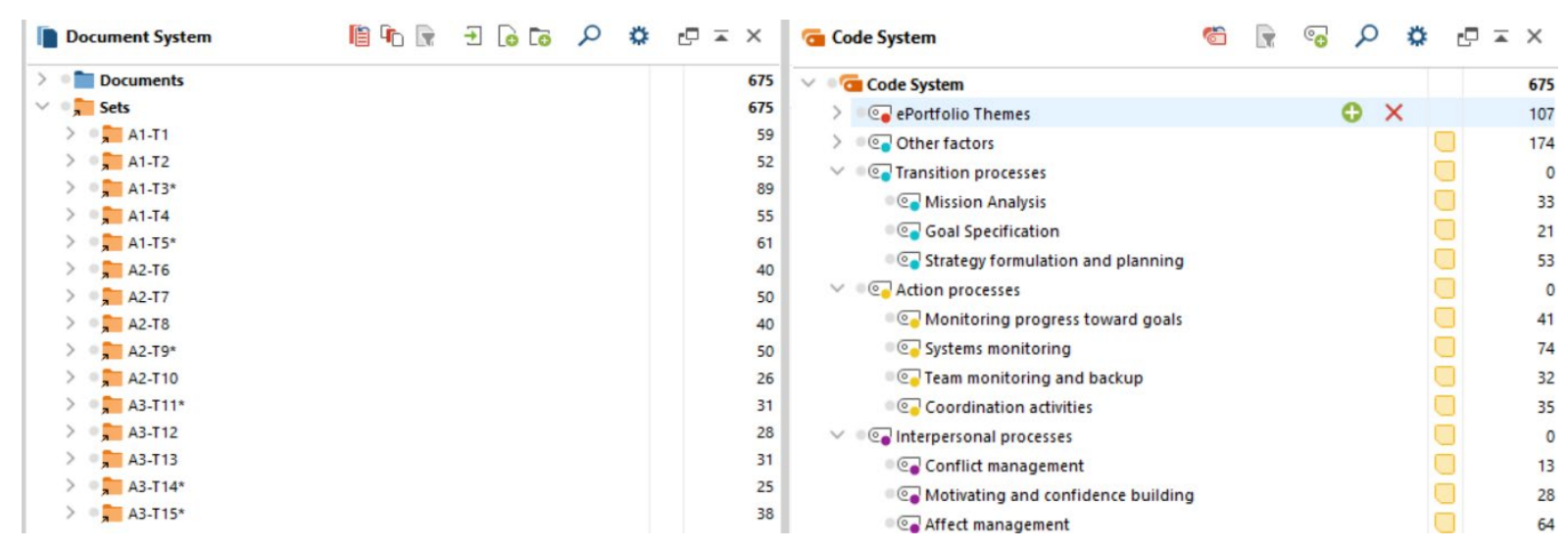

Figure 2. E-portfolio theme categorization and analysis in MAXQDA 
Researchers used MAXQDA ${ }^{\mathrm{TM}}$ (Analytics Pro, Ver.2020), a software program designed for computer-assisted qualitative and mixed methods analysis of data, text, and multimedia. Each student submitted three separate e-portfolios created as part of three team interactions. These documents were then de-identified and numerically coded. This procedure resulted in 15 separate sets of data, each set corresponding to one of the 15 virtual teams (see Fig 2). Each set of e-portfolio data were then examined in line with the procedure for an inductive content analysis (Silverman, 2004). In the initial step, following the taxonomy of team processes (Marks et al., 2001), researchers worked independently to examine the e-portfolio responses for recurring general themes corresponding to one of the following process dimensions of the taxonomy: transition, action, and interpersonal processes.

In the second step, researchers revisited the responses assembled in each main category, and through open coding procedures these responses were segmented into specific meaningful expressions (units of meaning), each representing a distinct lower-lever dimension (subcategories) as described in the taxonomy (for example: a unit of meaning extracted from the category 'transition processes' linked to $\rightarrow$ 'mission analysis' or $\rightarrow$ 'goal specification' $\rightarrow$ or 'strategy formulation and planning'). This procedure was repeated until all new units of meanings were extracted from datasets. In the last step, units of meanings, main categories, and subcategories were compared to one another across all responses to identify contextual commonalities and possible inconsistencies. 


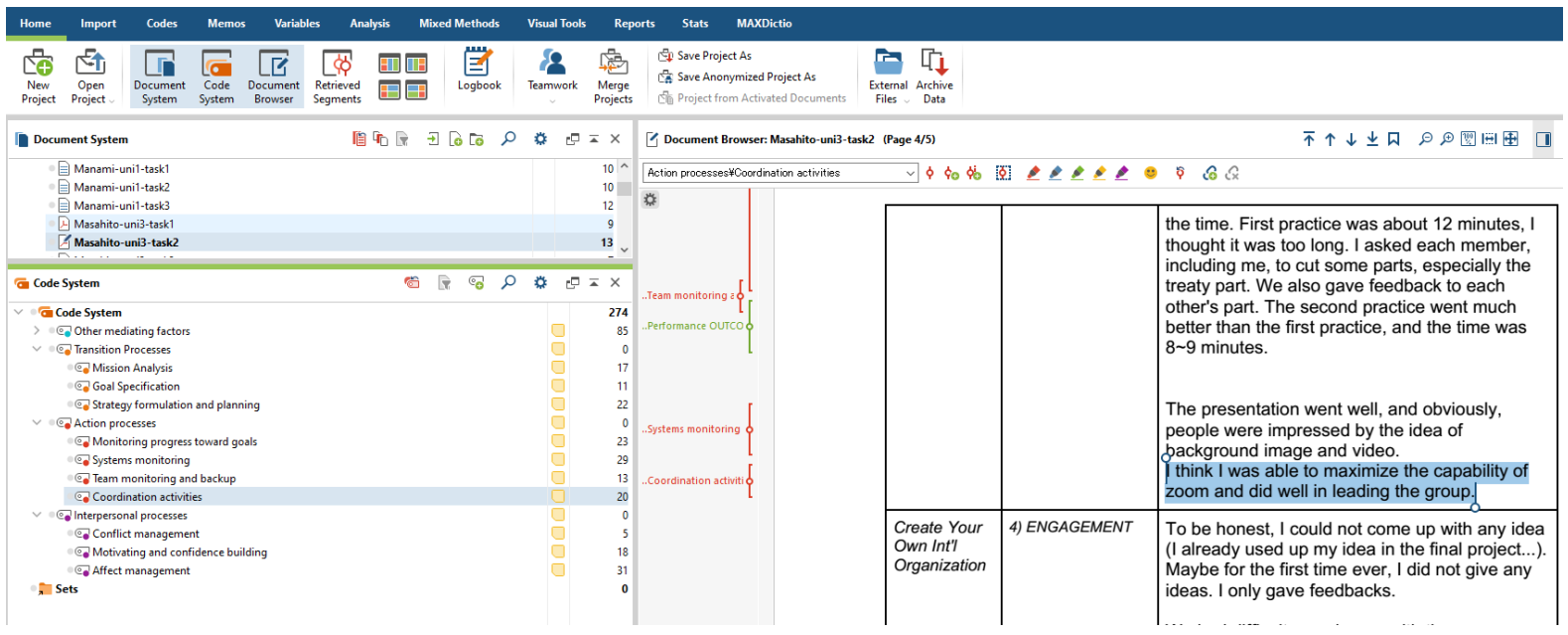

Figure 3. Open coding procedure using MAXQDA software

There have been 65 cases that involved a disagreement between researchers during coding of e-portfolio data into 3 main categories and 10 subcategories. The interrater reliability test resulted in $83.50 \%$ interrater agreement. McHugh (2012) suggests that $80 \%$ agreement should be the minimum acceptable interrater agreement.

\section{Results}

Each participant has created three e-portfolios for each task performed in their respective virtual teams. Thus, researchers analysed a total of sixty individual e-portfolios created and shared by twenty students (Fig 4). Teams 1-5 worked on assignment 1 and their members' entries produced 316 units of meaning related to their teamwork dynamics, whereas teams 610 and teams 11-15 worked on assignments 2 and 3, producing 206 and 153 units of meaning, respectively. Twenty e-portfolios yielded 675 units of meaning in total, from which 394 units (58.4\%) have been found to be directly related to team processes. 


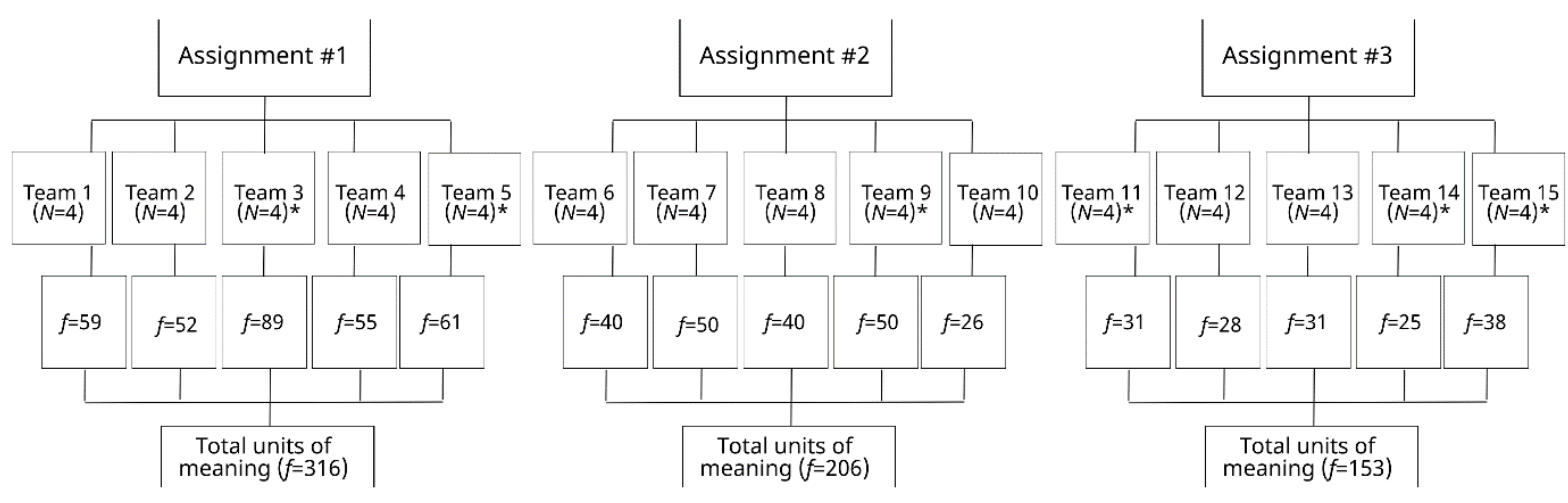

Note: Star symbol $\left(^{*}\right)$ shows virtual teams composed of students from all three participating universities

Figure 4. Frequency distribution across all assignments in e-portfolio data ( $\mathrm{f}=675)$

From the analysed e-portfolios (Fig 5), it can be observed that across all Input-ProcessesOutcomes (I-P-O) themes, Systems monitoring/Action processes (13.0\%), Affect management/Interpersonal processes (11.3\%), and Strategy formulation and planning/ Transition processes $(9.3 \%)$ have been crucial in invigorating virtual teams toward task accomplishment. In addition, themes related to Action processes, such as Monitoring progress toward goals (7.2\%) and Coordination activities (6.2\%) have often been highlighted by virtual teams. In contrast, themes related to Goal specification/Transition processes $(3.7 \%)$ and Conflict management/Interpersonal processes $(2.3 \%)$ have been least frequently reflected in the data. To various degrees, e-portfolio data also seem to highlight the role of team inputs (e.g., language skills, collaborative learning, general learning environment, technology, etc.) and outcomes (i.e., affective and performance) during virtual team's task accomplishment. 


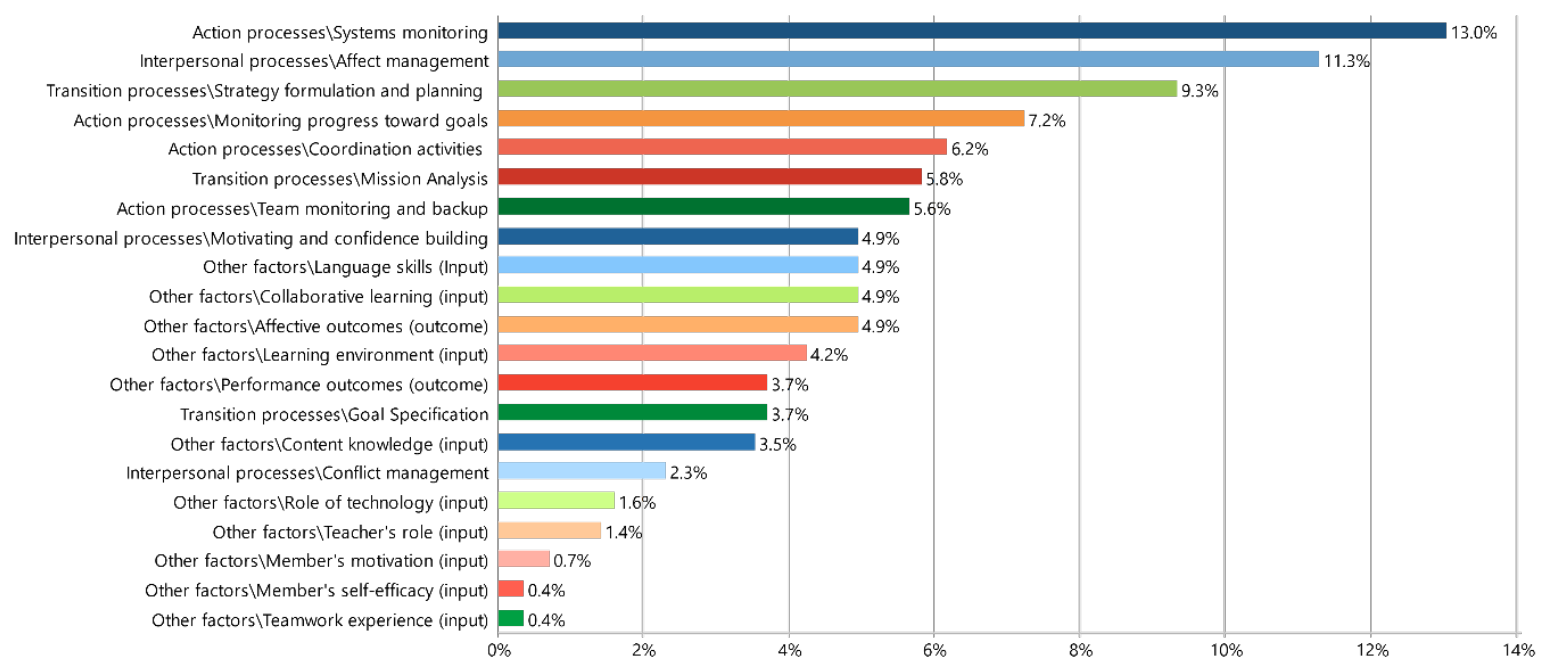

Figure 5. All IPO themes extracted from e-portfolio data $(\mathrm{f}=675)$

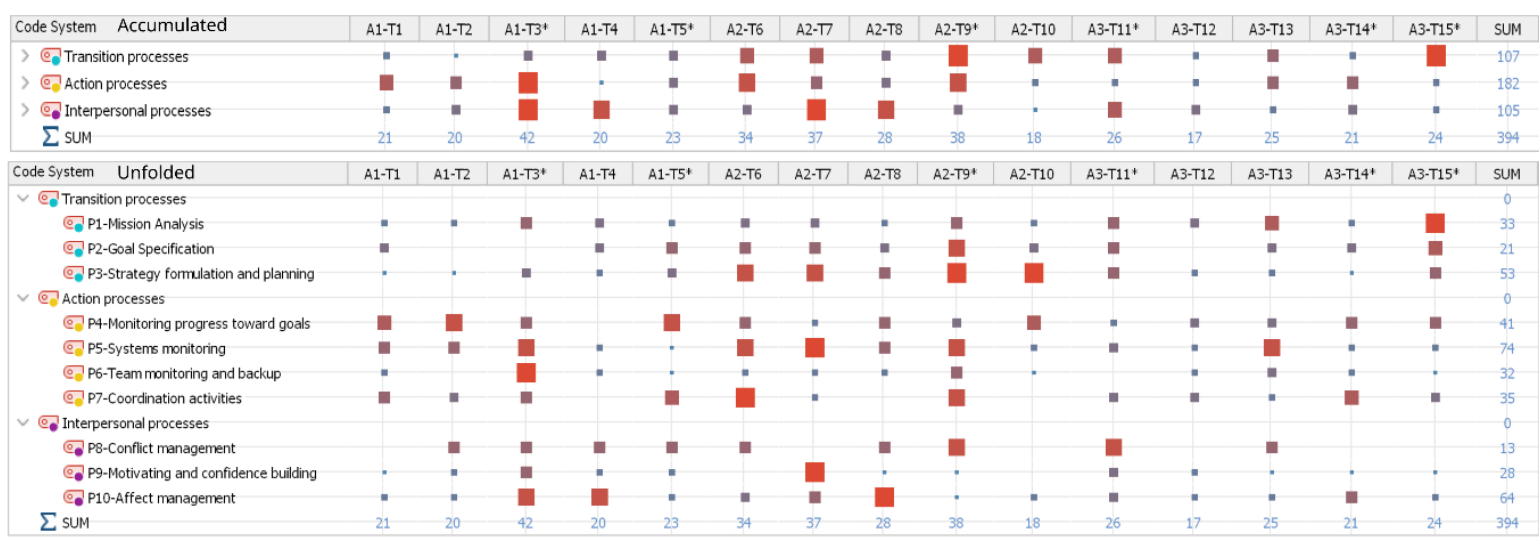

Figure 6. Distribution of code frequencies across virtual team e-portfolios in MAXQDA

Researchers used MAXQDA's Code Matrix Browser to visualize the frequency distribution of codes (e.g. related to team processes) across virtual team e-portfolio sets. The matrix, as shown in Figure 6, provides an overview of how many document segments from each student's eportfolio have been assigned a specific code for each existing code. The symbols at the conjunction points represent the number of segments that were coded with a specific code. The larger the symbol of a node, the more coded segments were assigned to the code in question. To discuss Figure 6 in more detail, in the following paragraphs, we will elucidate some of the 
interesting cases emerging from the data. Additionally, to support Figure 6, we have provided

Figure 7 below with an overview of students' e-portfolio entries related to each team process.

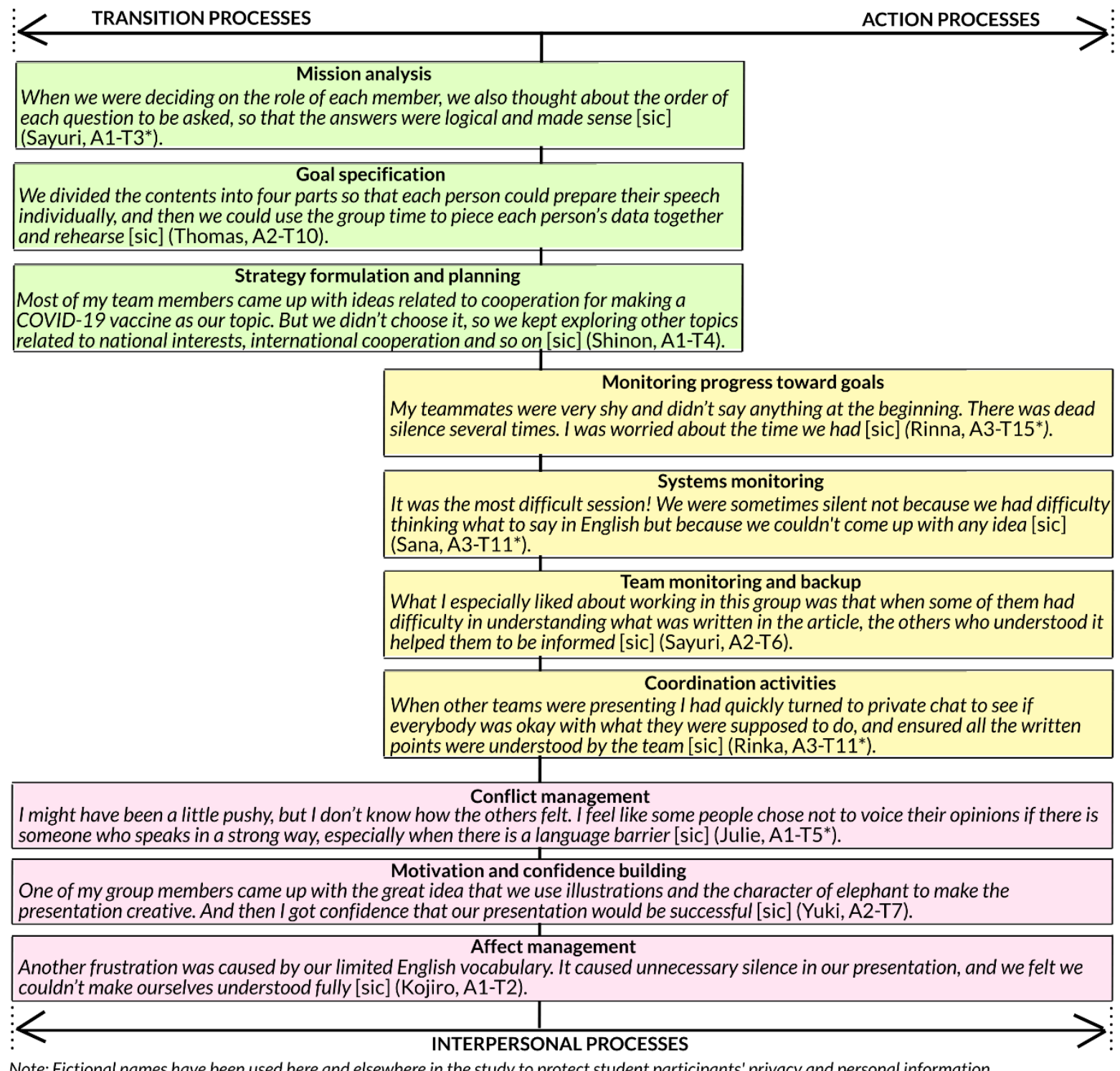

Note: Fictional names have been used here and elsewhere in the study to protect student participants' privacy and personal information.

Figure 7. Manifestation of team processes in students' e-portfolio entries (adapted from

Marks et al., 2001: 364)

\section{Transition processes}

\section{Mission analysis}


Results suggest that several virtual teams, especially those with diverse membership base, have been actively involved in the interpretation and evaluation of their teams' mission. (Each of our members introduced their articles, and then we decided which one article we would use for our project [sic]. Sana, A1-T3*). These teams also attempted, sometimes unsuccessfully, to identify their main tasks and the environmental conditions, available team resources, and time constraints (For a long time we discussed how to present and who should do each part. The problem was that we could not easily decide on how to perform a puppet or music show on the Zoom [sic]. Ami, A2-T6). The process of interpreting a mission also included verbal discussions to ensure that all members have a common vision of their team's objectives (When we were deciding on the role of each member, we also thought about the order of each question to be asked, so that the answers were logical and made sense [sic]. Sayuri, A1-T3*)

\section{Goal specification}

During goal specification processes virtual teams sought to identify and prioritize their goals and subgoals for mission accomplishment. E-portfolio analyses indicate that half of the teams went through this process to develop and assign overall mission goals and subgoals (We set up several goals, such as a) making the presentation as short as possible, b) using less specialized term, c) using less politics/treaty/agreements, more real-life examples/solutions, d) making it visual, such as using background videos on Zoom, e) adding variety to attract the viewers' attention [sic]. Masahito, A2-T9*). The teams' goal/subgoals also indicated what and how much must have been accomplished by a specified time (Due to the lack of time for preparation, we decided to mix the picture-story show and teacher-student discussion show [sic]. Rinka, A2-T6) and within certain quality standards (Based on this idea, we finally found a common ground for creating our own international organization [sic]. Sayuri, A3-T13). 


\section{Strategy formulation and planning}

As illustrated in Figure 5, e-portfolio entries suggest that many teams have been active in the formulation of alternative courses of action for mission accomplishment. This process involved decision making about how team members could achieve their missions (Rather than deciding on the topic through headlines search, we thought it would be efficient first to choose the topic which we were familiar with, and later research it separately and more extensively [sic]. Masahito, A1-T5*). It also involved discussing expectations and relaying task-related information (We knew that using the theories to make a presentation would bore the listeners. With this in mind, we decided to make it more like storytelling [sic]. Subaru, A2-T10) and communicating plans to all team members (We had plans to rehearse our presentation on the evening after the second day or the morning of the next day [sic]. Eijun, A2-T8). E-portfolio data showed that the ratio of deliberate planning, contingency planning, and reactive strategy adjustment was approximately 25:20:55, indicating that virtual teams often tried to alter their existing strategy or plans in response to unanticipated changes in the environment.

\section{Action processes}

\section{Monitoring progress toward goals}

One could also observe that several teams were actively tracking their progress toward mission accomplishment by interpreting the current situation in terms of what needed to be accomplished for goal attainment (During the group meeting, we got deeply involved in the lecture's contents and specific examples of organizations, however overall, we were struggling to organize our ideas [sic]. Anna, A2-T12). Some team members sought to provide feedback to their team on its goal accomplishment status so that members could determine their progress (We have experienced running out of time during planning and not being able to present the 
issue properly earlier, so I tried to monitor time and keep the team informed [sic]. Julie, A1T5*). Teams also tended to assess in real-time the discrepancies between their goals and their current situation (I was thinking that we should have gone through the article all together rather than each of us reading the article and then discussing it, because the latter took so much time[sic]! Rinka, A1-T1). It should also be noted that according to e-portfolios, teams that spent less time in the transition phase and struggled to formulate their strategy were likely to spend more time in the action phase trying to monitor every progress toward their goals.

\section{Systems monitoring}

In Figure 5, systems monitoring appears to be the most frequently mentioned process-related characteristic of virtual teamwork in this specific case. From the data, one could observe that many teams tracked their internal resources and other environmental conditions during taskwork. Some teams focused on internal systems monitoring by tracking team resources, such as skills, equipment, and other information that was generated within the team (Fortunately we had good English speakers, so we did not have any big problems with this assignment. Everything went smoothly [sic]. Kojiro, A2-T6). Other teams were involved in environmental monitoring, tracking the external conditions relevant to their team's goal ( We were the last team to receive our topic and instructions, and our topic was about Middle East, which we are not very knowledgeable about [sic]. Rinna, A2-T8). A few teams were forced to monitor their internal and external environments (We were interested in music show, but we did not know how to do this online; eventually, we gave up. Some of us can play the instruments. However, we thought we could not perform well online [sic]. Homa, A2-T7)

Team monitoring and back up 
Team monitoring and backup processes have been observed across many teams, most notably in $\mathrm{A} 1-\mathrm{T} 3 *$ and $\mathrm{A} 2-\mathrm{T} 9 *$. These and other teams witnessed how their members tried to assist each other to perform taskwork by providing verbal feedback or coaching (Since I already know about theories of international relations, I explained them to other teammates by using simple real-life examples [sic]. Subaru, A1-T1; other members explained clearly by using easy English words [sic]. Sana, A1-T3*). In some instances, they behaviourally assisted teammates in carrying out actions (My drawing and the example of COVID helped the class to introduce soft power in our presentation [sic]. Masahito, A1-T5*). E-portfolio data showed numerous examples when members watched out for one another and warned of possible problems (To do the assignment smoothly and to finish it in time, I informed my team mates how much more time we had, every now and then [sic]. Rinna, A1-T4).

\section{Coordination activities}

Coordination activities have been mentioned often in students' e-portfolios. These statements referred to the handling of synchronous activities and involved information exchange and mutual adjustment of action (So, first, I asked the team members about any current events they knew or might be interested in, and we all agreed to engage in research on the ban of Tik Tok app in the United States [sic]. Masahito, A1-T5*). This feature of teamwork seems to be closely connected with the taskwork required of the team (While we had difficulty with deciding our team's topic, I found news about ASEAN and then we finalized our search and started our discussion about ASEAN organisation [sic]. Ami, A1-T1). Coordination often occurred during action phases (One of my goal was to make presentation short, so I measured the time. First practice was about 12 minutes, and I thought it was too long. I asked each member to cut some parts, especially the treaty part, and I also did this [sic]. Masahito, A2-T9*) as well as during transition phases (In the beginning, because we did not have time to do a research together, 
nor practice for the presentation, I suggested splitting the project into 4 parts, with one part for each person [sic]. Rinka, A2-T6).

\section{Interpersonal processes}

\section{Conflict management}

Although team members seem to have built constructive and friendly relationships with each other, from e-portfolios, one can observe two forms of conflict management processes that were used by some members to mitigate conflict. For instance, some members engaged in preemptive conflict management which included establishing conditions to prevent or guide team conflict before it occurred (When we discussed the presentation format, everyone suggested ideas about how to do it. I think, at that time, everyone showed interest and listened patiently to each other's suggestions so that we could avoid conflict [sic]. Sayuri, A2-T6). Other members voiced sentiments related to reactive conflict management which involved working through interpersonal disagreements among team members (Finally other teammates started talking but they gave very different ideas. There was a conflict because everyone wanted to work on their idea, and I felt that everyone held something against each other [sic]. Rinka, A3-T11*).

\section{Motivating and confidence building}

Motivating and confidence building occasionally occurred during virtual team interactions. These processes were evident in members' intent to generate and preserve a sense of collective confidence, motivation, and cohesion (We were always in the good mood, which enabled us to freely voice our opinions. [sic] Mizuki, A3-T11*; But other students participated in the lesson actively, so I was impressed and motivated. [sic] Yuki, A1-T4). Some members motivated 
others by communicating their beliefs about each other's ability and competence on certain tasks (After our presentation, many students voted for our organisation. One of my teammates said to me 'Classmates proved your idea was great! Of course, I knew that! :)' It gave me courage [sic]! Ami, A3-T12).

\section{Affect management}

Affect management was evident when during various taskwork members regulated emotions related to social cohesion (Despite the ease of online conversation visible on the screen, talking with others was tough [sic]. Eijun, A1-T5*), frustration (I soon regretted it because there was a lot of research that needed to be done [sic]. Rinka, A2-T6), and excitement (I really enjoyed the groupwork [sic]. Shinon, A1-T4). In the meantime, none of the students mentioned techniques used to regulate emotions, such as attempting to calm members down or control frustration levels. However, some members attempted to boost team morale by being empathetic toward them (I know how hard it is to speak in a foreign language, so I tried to speak understandably, check if he understood me, and overall kept the situation relaxed [sic]. Julie, A1-T5*).

\section{Discussion}

This study aimed to map the occurring team processes along transition, action, and interpersonal phases by thematically examining the perceptions of students about their virtual teamwork. The results further validate the taxonomy of team processes indicating that virtual learning teams indeed act as 'multitasking units that perform multiple processes simultaneously and sequentially to orchestrate goal-directed taskwork' (Marks et al., 2001: 356). The authors of the study posit that regardless of environmental conditions of the COVID-19 pandemic or 
membership diversity, virtual teamwork in the online learning context is dynamic by nature and is characterized by multiphase and episodic interaction among team members working to accomplish a shared goal.

The results obtained from the inductive content analysis of student e-portfolios show that these processes vary considerably from team to team, and from task to task. The findings are consistent with previous studies suggesting that transitional processes are particularly crucial for explaining students' perceptions of goal accomplishment, whereas interpersonal processes are important for explaining perceptions of effective learning and satisfaction with the teamwork. (Bravo et al., 2016).

E-portfolios also indicated that collaboration persisted significantly over conflict and virtual teams that effectively formulated their goals and strategies, irrespective of their membership diversity, obtained better results during the action phase. During the periods when teams conducted activities leading to goal accomplishment, the most cited factors contributing to effective teamwork experiences were systems monitoring and coordination activities. Previous studies suggested that students often struggle to achieve the desired learning outcomes from team working because of considerable pressure to complete tasks before tight deadlines and other commitments which render active participation problematic (Whatley, 2006; Wilson et al., 2018).

In addition, the findings suggest that interpersonal processes must be taken into serious consideration to understand the development of mutually shared cognition among students resulting in higher perceived team performance (den Bossche et al., 2006). Overall, it is revealed that virtual teams comprised of students from multiple universities can collaborate on 
learning tasks and proceed through all processes smoothly when there is elaborate brainstorming and discussion of group organization and task work, a positive atmosphere, and acceptance of contribution from members (Verstegen et al., 2018).

A key theoretical question of this study was to explore how team processes evolve temporally across different virtual teams and tasks. To examine the role of process in performance episodes we employed a recurring phase model of team processes (Marks et al., 2001). Team performance is best analysed as a series of related Input-Process-Outcome episodes, and this study posits that virtual teamwork fits this framework as well. A careful examination of eportfolios sets corresponding to each team allowed researchers to create an additional map showing how selected virtual teams were engaged in different types of taskwork at different phases of task accomplishment (see Fig 8). Detailed observation of extracted themes helped researchers better understand the rhythms of processes taking place during each team's completion of virtual tasks. Figure 8 is not a mathematically precise model, rather a result of careful observation by researchers of micro-events, interruptions and standstills occurring during virtual teamwork. Notably, the analysis was assisted by the findings illustrated in Figure 6. In the study, some teams were focused on activities directly related to goal execution, whereas other teams were reflecting on recent experiences and planning their next action. According to this model, virtual teams tend to compare current performance levels against goals and derive performance gaps (Marks et al., 2001:360-361). Figure 8 shows seven unique types of performance episodes which virtual teams experienced during their taskwork. For example, teams 6 and 9 had experienced a relatively fast rhythm of task accomplishment, as observed through the repetitive cycles in transition and action phases. Team 5 is depicted as undergoing a short transition period before it enters a long period of sustained virtual team 
action, whereas team 15 experiences a diametrically opposite scenario. Teams 3 and 8 fall between the previous three cycles, and Team 1 experiences a cycle with delayed onset.
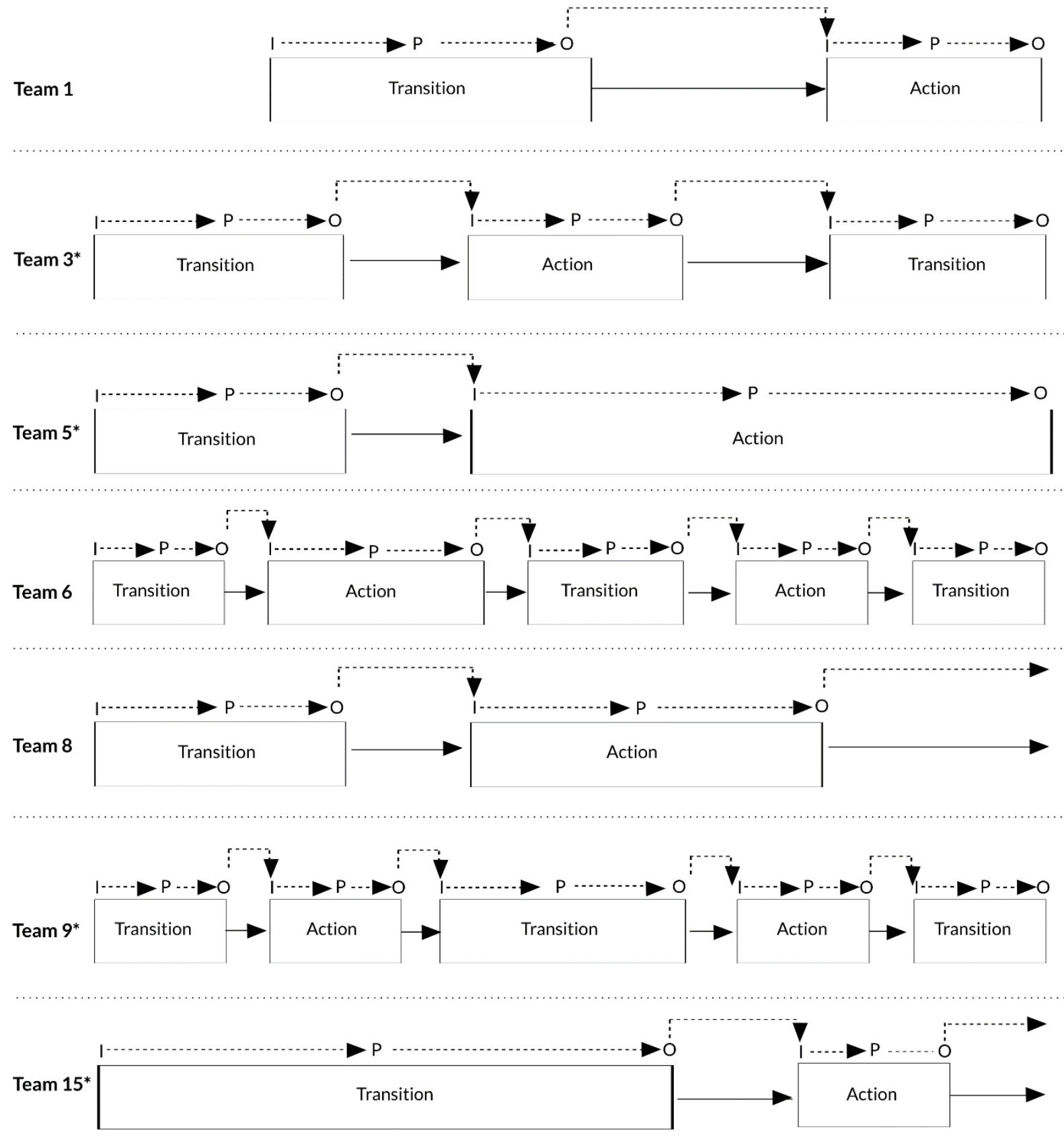

\section{Time}

Figure 8 . The rhythms of virtual teamwork in selected cases

Furthermore, processes occur repeatedly during virtual team episodes, affected by inputs and influencing outcomes within action and transition phases and across tasks and time. According 
to the model (Marks et al., 2001), normally, during the time when teams move back and forth between action and transition phases, the nature of team process also transforms. For example, virtual teamwork processes that involve mission analysis, goal formulation, strategy planning, and evaluation occur more frequently in transition phases, whereas system monitoring, back up, and coordination processes are more likely to extend the action phases of goal accomplishment. The current study validates the model in that the frequency and duration of action and transition phase variability depends on various factors, including team composition, members' knowledge and skills, nature of task, technology, learning environment, leadership, initiative, and so forth. Especially, as observed in the study, virtual team composition (i.e., multi-university vs mono-university teams) appears to have no relationship with the episodic variability of processes in these teams. In contrast, the results suggest that virtual teams with more diverse institutional base (marked with asterisk in Figures 6-8) appear to undergo the team processes more dynamically compared to mono-university virtual teams.

In sum, this study showed that team effectiveness is not only a consequence of virtual team members' talents and resources but also various processes which team members willingly or unwillingly initiate to interact with one another and achieve shared goals. By understanding the processes that students employ when learning together in virtual teams, especially during COVID-19 pandemic, teachers would be better positioned to design instructional materials and assignments for effective online collaborative learning.

\section{Conclusion: Implications for the theory and pedagogy of virtual teamwork}

Due to the increased use of technology and its potential to support collaborative and authentic learning tasks (Hu, 2015), virtual teamwork format is significantly growing in higher education 
worldwide, and one can expect this trend to persist in both current and post-COVID-19 learning environments.

One of the main theoretical implications of this study was to further research in the fields of elearning, collaborative learning, and communication technology in higher education by using the concept of virtual teamwork to highlight the role of team processes. While teamwork research has traditionally viewed 'inputs-processes-outcomes' as organically intertwined components of the concept, few studies have looked specifically at temporal processes in a university-level collaborative e-learning context. The present study sought to shift its focus from the question of ' what' makes teams effective to addressing the question of 'what it takes for the virtual teams [temporally]' to be effective (Ilgen et al., 2005; Martins et al., 2004). By doing so, this paper has explored several important but currently not sufficiently studied components of virtual teamwork involving university students, such as systems monitoring, affect management, strategy formulation and planning, monitoring progress toward goals, coordination activities and others. Empirical investigation of these categories by analysing students' e-portfolios helped to address several key questions posed recently by researchers of virtual teamwork and collaborative online learning (Herrera-Pavo, 2021; Hu, 2009; Page et al., 2020; Yoon \& Johnson, 2008).

In addition, the findings of the study have some pedagogical implications. As it was stated earlier, working in virtual learning teams is different from learning online with peers, and therefore, teachers need to develop and implement various teaching strategies to advance this learning format. Based on the study's findings, we suggest a few practical points to be taken into consideration. First, before initiating virtual teamwork projects instructors should explicitly teach their students essential skills, especially focusing on collaboration and communication among members of virtual teams. This instruction should prioritize strategies that would allow students to work effectively in the transition and action phases, for example, 
to assign roles and tasks, discuss missions, brainstorm initial ideas, formulate goals and strategies, coordinate and back up each other's work.

Secondly, given that students who previously had no virtual teamwork experience seemed to have struggled to collaborate with their team members, teachers should nurture students' ability to effectively work remotely. For example, pedagogic interventions for remote collaboration might include setting clear and shared expectations, collaboratively creating artefacts on a shared platform, and collectively and individually reflecting on their contributions (Vielma \& Brey, 2020).

Finally, previous research suggested that virtual learning teams go through team building stages more quickly than face-to-face teams (Yoon \& Johnson, 2008). To enable a positive virtual teamwork environment, we agree with $\mathrm{Hu}$ (2015) that instructors should provide students with opportunities to have elaborate introductions for establishing their identity, engaging in team building activities to develop trust, and drafting and agreeing upon a team contract to minimize and manage future conflicts.

\section{Limitations and suggestions for future research}

\section{Underlying conditions}

Although this study provides new insights into the virtual team processes in an e-learning environment, the fact that the research was conducted in a limited socio-cultural and geographic setting in which students had a relatively easy access to high-speed communication technology (i.e., in Japan), denotes one important limitation. Therefore, this study may lack some generalizability regarding the application of findings to e-learning environments in countries with distinct socio-cultural conditions as well as those in which learners have poorer access to broadband Internet. Future studies might be conducted to fill this gap. Also, because 
the current study involved participants enrolled in an undergraduate online course conducted in a live-streaming mode, future studies might shed light on the virtual team processes in other formal (e.g., graduate and postgraduate levels), non-formal (e.g., workplace learning) and informal learning situations supported by synchronous, asynchronous, or hybrid environments.

\section{Theoretical lens and e-portfolio methodology}

First, the current study utilized e-portfolios to explore virtual team processes through the theoretical lens of Marks et al. (2001) team processes model. The open coding procedure and inductive content analysis have resulted in the extraction of numerous factors related to inputs and outcomes. Because previous research has already established an integral connection among 'inputs-processes-outcomes', in this study researchers have deliberately excluded inputs and outcomes from the analysis. Secondly, although the choice of e-portfolios proved useful for encouraging students' active learning and provided a tool for structured peer-assessment, the present study did not specifically address the question of how e-portfolio methodology could be refined or applied in the research of virtual teamwork. To overcome this shortcoming, it is important that future studies elaborate on e-portfolio methodology in greater detail.

\section{Longitudinal data}

Finally, in this study, researchers examined virtual teamwork processes at one point in time. Although this study provides important insights into action, transition and interpersonal processes occurring during an intensive online course, it is necessary for future research to analyze the temporal processes of a virtual teamwork longitudinally. Since virtual teamwork is, by definition, dependent on dynamic individual behavior of virtual team members, future research should employ longitudinal data on multiple levels of an educational organization. 


\section{References}

Abarca, V. M. G., Palos-Sanchez, P. R., \& Rus-Arias, E. (2020) Working in Virtual Teams: A Systematic Literature Review and a Bibliometric Analysis. IEEE Access, doi: 10.1109/ACCESS.2020.3023546

Alexander, P. M. (2006). Virtual teamwork in very large undergraduate classes. Computers \& Education, 47(2), 127-147.

Almarzooq, Z., Lopes, M., \& Kochar, A., (2020) Virtual Learning during the COVID-19 Pandemic: A Disruptive Technology in Graduate Medical Education. Journal of the American College of Cardiology, doi: https://doi.org/10.1016/j.jacc.2020.04.015

Balaban, I., Mu, E., \& Divjak, B. (2013). Development of an electronic Portfolio system success model: An information systems approach. Computers and Education, 60(1), $396-411$.

Baltes, B. B., Dickson, M. W., Sherman, M. P., Bauer, C. C., \& LaGanke, J. S. (2002). Computer-mediated communication and group decision making: A meta-analysis. Organizational Behaviour and Human Decision Processes, 87, 156 - 179.

Beech, N., \& Anseel, F. (2020). COVID-19 and its impact on management research and education: Threats, opportunities and a manifesto. British Journal of Management, 31(3), 447-449.

Bell, B. S., \& Kozlowski, S. W. J. (2002). A typology of virtual teams. Group \& Organization Management, 27, 14-49.

Bergiel, B., Bergiel, E., \& Balsmeier, P. (2008). Nature of virtual teams: A summary of their advantages and disadvantages. Management Research News, 31, 99-110. 
Blackburn, R., Furst, S., \& Rosen, B. (2003). Building a winning virtual team. In C. B. Gibson, \& S. G. Cohen (Eds.), Virtual teams that work. Creating Conditions for Virtual Team Effectiveness. (pp. 95-120). San Francisco: Jossey-Bass.

Boellstorff, T., Nardi, B., Pearce, P., \& Taylor, T.L. (2012). Ethnography and Virtual Worlds. A Handbook of Method. Princeton and Oxford: Princeton University Press.

Brannick, M.T, Salas, E., \& Prince, C. (1997). Team performance and measurement: Theory, methods, and applications. Mahwah, NJ: Lawrence Erlbaum Associates.

Bravo, R., Catalán, S., \& Pina, J. M. (2019). Analysing teamwork in higher education: an empirical study on the antecedents and consequences of team cohesiveness. Studies in Higher Education, 44(7), 1153-1165.

Bravo, R., Lucia-Palacios, L., \& Martin, M.J. (2016). Processes and outcomes in student teamwork. An empirical study in a marketing subject. Studies in Higher Education, $41(2), 302-320$.

Britton, E., Simper, N., Leger, A., \& Stephenson, J. (2017). Assessing teamwork in undergraduate education: a measurement tool to evaluate individual teamwork skills. Assessment \& Evaluation in Higher Education, 42(3), 378-397.

Cannon-Bowers, J. A., Tannenbaum, S. I., Salas, E., \& Volpe, C. E. (1995). Defining competencies and establishing team training requirements. In R. A. Guzzo, E. Salas, \& Associates (Eds.), Team effectiveness and decision making in organizations (pp. 333380). San Francisco: Jossey-Bass.

Cannon-Bowers, J. A., \& Bowers, C. (2011). Team development and functioning. In S. Zedeck (Ed.), APA handbooks in psychology ${ }^{\circledR}$. APA handbook of industrial and organizational psychology, Vol. 1. Building and developing the organization (p. 597-650). American Psychological Association. 
Cappel, J. J., \& Windsor, J. C. (2000). Ethical decision making: A comparison of computersupported and face-to-face group. Journal of Business Ethics, 28, 95-107.

Chudoba, K. M., Wynn, E., Lu, M., \& Watson-Manheim, M. B. (2005). How virtual are we? Measuring virtuality and understanding its impact in a global organization. Information Systems Journal, 15, 279-306.

Cogliser, C. C., Gardner, W. L., Gavin, M. B., \& Broberg, J. C. (2012). Big five personality factors and leader emergence in virtual teams: Relationships with team trustworthiness, member performance contributions, and team performance. Group \& Organization Management, 37, 752-784.

Costa, P. L., Passos, A. M., \& Bakker, A. B. (2014). Team work engagement: A model of emergence. Journal of Occupational and Organizational Psychology, 87(2), 414-436.

Daft, R. L., \& Lengel, R. H. (1984). Information richness: A new approach to managerial behaviour and organization design. Research in Organizational Behaviour, 6, 191-233.

den Bossche, P. V., Gijselaers, W. H., Segers, M., \& Kirschner, P. A. (2006). Social and cognitive factors driving teamwork in collaborative learning environments: team learning beliefs and behaviours. Small Group Research, 37(5), 490-521.

Dickinson, T. L., \& McIntyre, R. M. (1997). A conceptual framework for teamwork measurement. In M. T. Brannick, E. Salas, \& C. Prince (Eds.), Team performance and measurement: Theory, methods, and applications (pp. 19-43). Mahwah, NJ: Lawrence Erlbaum Associates.

Dulebohn, J. H., \& Hoch, J. E. (2017). Virtual teams in organizations. Human Resource Management Review, 27, 569-694. 
Fisher, D.M. (2014). Distinguishing between taskwork and teamwork planning in teams: Relations with coordination and interpersonal processes. Journal of Applied Psychology, $99(3), 423-436$.

Gibson, C. \& Cohen, S. (2003). In the Beginning: Introduction and Framework. In C. B. Gibson, \& S. G. Cohen (Eds.), Virtual teams that work. Creating Conditions for Virtual Team Effectiveness (pp. 1-13). San Francisco: Jossey-Bass.

Graetz, K. A., Boyle, E., Kimble, C., Thompson, P., \& Garloch, J. (1998). Information sharing in face-to-face, teleconferencing and electronic chat groups. Small Group Research, 29, $714-743$.

Griffith, T. L., \& Neale, M. A. (2001). Information processing in traditional, hybrid, and virtual teams: From nascent knowledge to transactive memory. Research in Organizational Behaviour, 23, 379-421.

Guth, S., \& Helm, F. (2010). Introduction. In S. Guth, \& F. Helm (Eds.), Telecollaboration 2.0: Language, Literacies and Intercultural Learning in the 21st Century (pp. 13-35). Bern: Peter Lang.

Guzzo, R. A., \& Dickson, M. W. (1996). Teams in organizations: Recent research on performance and effectiveness. Annual Review of Psychology, 47, 307-338.

Hansen, R. S. (2006). Benefits and problems with student teams: suggestions for improving team projects, Journal of Education for Business, 82:1, 11-19

Herrera-Pavo, M. Á. (2021). Collaborative learning for virtual higher education. Learning, Culture and Social Interaction, https://doi.org/10.1016/j.lcsi.2020.100437

Hertel, G., Geister, S., \& Konradt, U. (2005). Managing virtual teams: A review of current empirical research. Human Resource Management Review, 15, 69-95. 
Hertel, G., Konradt, U., \& Orlikowski, B. (2004). Managing distance by interdependence: Goal setting, task interdependence and team-based rewards in virtual teams. European Journal of Work and Organizational Psychology, 13, 1-28.

Hjorth, L., Horst, H., Galloway, A., \& Bell, B. (2017). Introduction. In: L. Hjorth, H. Horst, A. Galloway \& B. Bell (Eds.), The Routledge Companion to Digital Ethnography. New York and London: Routledge.

Holtz, K., Orengo Castella, V., Zornoza Abad, A., \& González-Anta, B. (2020). Virtual team functioning: Modeling the affective and cognitive effects of an emotional management intervention. Group Dynamics: Theory, Research, and Practice, http://dx.doi.org/10.1037/gdn0000141

Hu, H. (2009). An international virtual team based project at undergraduate level: Design and assessment. Marketing Education Review, 19(1), 17-22.

Hu, H. (2015). Building virtual teams: Experiential learning using emerging technologies. ELearning and Digital Media, 12(1), 17-33.

Huang, W. W., Wei, K.-K., Watson, R. T., \& Tan, B. C. Y. (2003). Supporting virtual teambuilding with a GSS: An empirical investigation. Decision Support Systems, 34, 359367.

Ilgen, D. R., Hollenbeck, J. R., Johnson, M., \& Jundt, D. (2005). Teams in organizations: From input-process-output models to IMOI models. Annual Review of Psychology, https://doi.org/10.1146/annurev.psych.56.091103.070250

Authors (2021)

Jamieson, P., Miglis, P., Holm, J., \& Peacock, J. (2008). Creating new generation learning environments on the university campus. Southbank. Vic.: WB Research Press. 
Jentsch, F., Barnett, J., Bowers, C. A., \& Salas, E. (1999). Who is flying this plane anyway? What mishaps tell us about crew member role assignment and air crew situational awareness. Human Factors, 41(1), 1-14.

Khalili, H. (2020). Online interprofessional education during and post-COVID-19 pandemic. Journal of Interprofessional Care, https://doi.org/10.1080/13561820.2020.1792424

Kirkman, B. L., Rosen, B., Tesluk, P. E., \& Gibson, C. B. (2004). The impact of team empowerment on virtual team performance: The moderating role of face-to-face interaction. Academy of Management Journal, 47, 175-192.

Klitmøller, A., \& Lauring J. (2013). When global virtual teams share knowledge: Media richness, cultural difference and language commonality. Journal of World Business, $48(3), 398-406$.

Kopp, B., Matteucci, M. C., \& Tomasetto, C. (2012). E-tutorial support for collaborative online learning: An explorative study on experienced and inexperienced e-tutors. Computers and Education, 58(1), 12-20.

Krumm, S., Kanthak, J., Hartmann, K. \& Hertel, G. (2016). What does it take to be a virtual team player? The knowledge, skills, abilities, and other characteristics required in virtual teams. Human Performance, 29(2), 123-142,

Leenders, R. T., van Engelen, J., \& Kratzer, J. (2003). Virtuality, communication, and new product team creativity: A social network perspective. Journal of Engineering and Technology Management, 20, 69-92.

LePine, J. A., Piccolo, R. F., Jackson, C. L., Mathieu, J. E., \& Saul, J. R. (2008). A metaanalysis of teamwork processes: tests of a multidimensional model and relationships with team effectiveness criteria. Personnel Psychology, 6(2), 273-307. 
Lurey, J. S., \& Raisinghani, M. S. 2001. An empirical study of best practices in virtual teams. Information \& Management, 38, 523-544.

Marks, M. A., Mathieu, J. E., \& Zaccaro, S. J. (2001). A temporally based framework and taxonomy of team processes. Academy of Management Review, 26, 356-376.

Martins, L. L., Gilson, L. L., \& Maynard, M. T. (2004). Virtual teams: What do we know and where do we go from here? Journal of Management, 30, 805-835.

Maznevski, M. L., \& Chudoba, K. M. (2000). Bridging space over time: Global virtual team dynamics and effectiveness. Organization Science, 11, 473-492.

Maznevski, M. L., \& Chudoba, K. M. (2000). Bridging space over time: Global virtual team dynamics and effectiveness. Organization Science, 11, 473-492.

McGrath, J. E. (1984). Groups: Interaction and performance. Englewood Cliffs, NJ: PrenticeHall.

McHugh, M. L. (2012). Interrater reliability: The kappa statistic. Biochemia Medica, 22, 276282.

Montoya-Weiss, M., Massey, A., \& Song, M. (2001). Getting it together: Temporal coordination and conflict management in global virtual teams. Academy of Management Journal, 44, 1251-1262.

Nunamaker, J. F. Jr., Briggs, R. O., Romano, N. C. Jr., \& Mittleman, D. D. (1998). The Virtual Office Work-Space: GroupSystems Web and Case Studies. In D. Coleman (Ed.), Groupware: Collaborative Strategies for Corporate LANs and Intranets. New York: Prentice-Hall.

Odenwald, S. (1996). Global work teams. Training \& Development, 50, 54-57. 
Page, A., Charteris, J., \& Berman, J. (2020). Using virtual teams to map digital new generation learning environments into tertiary online learning spaces. International Journal of Online Graduate Education, http://doi.org/10.5281/zenodo.3934649

Pineda, R. C., \& Lerner, L. D. (2006). Goal attainment, satisfaction and learning from teamwork. Team Performance Management, 12(5/6), 182-191.

Prince, C., \& Salas, E. (1993). Training research for teamwork in the military aircrew. In E. L. Wiener, B. G. Kanki, \& R. L. Helmreich (Eds.), Cockpit research management (pp. 337366). Orlando, FL: Academic Press.

Riopelle, K., Gluesing, J. C., Alcordo, T. C., Baba, M., Britt, D., McKether, W., Monplaisir, L., Ratner, H. H., \& Wagner, K. H. (2003). Context, task, and the evolution of technology use in global virtual teams. In C. B. Gibson, \& S. G. Cohen (Eds.), Virtual teams that work. Creating Conditions for Virtual Team Effectiveness. (pp. 239-264). San Francisco: Jossey-Bass.

Shapiro, D. L., Furst, S. A., Spreitzer, G. M., \& Von Glinow, M. A. (2002). Transnational teams in the electronic age: Are team identity and high performance at risk? Journal of Organizational Behaviour, 23, 455-467.

Silverman, D. (2004). Qualitative research: Theory, Method and Practice. Second Edition. London, Thousand Oaks and New Delhi: Sage Publications.

Simons, T. L., Pellad, L. H., \& Smith, K. A. (1999). Making use of difference: Diversity, debate, and decision comprehensiveness in top management teams. Academy of Management Journal, 42, 662-673. 
Simons, T. L., \& Peterson, R. S. (2000). Task conflict and relationship conflict in top management teams: The pivotal role of intragroup trust. Journal of Applied Psychology, $85,102-111$.

Smolek, J., Hoffman, D., \& Moran, L. (1999). Organizing teams for success. In E. Sundstrom (Ed.), Supporting work team effectiveness (pp. 24-62). San Francisco: Jossey-Bass.

Stout, R. J., Cannon-Bowers, J. A., Salas, E., \& Milanovich, D. M. (1999). Planning, shared mental models, and coordinated performance: An empirical link is established. Human Factors, 41(1), 61-71.

Thompson, J. D. (1967). Organizations in actions. New York: McGraw-Hill.

Varela, O. \& Mead, O. (2018). Teamwork skill assessment: Development of a measure for academia. Journal of Education for Business, 93, 172-182.

Verstegen, D. M. L., Dailey-Hebert, A., Fonteijn, H.T.H., Clarebout, G. \& Spruijt, A. (2018). How do virtual teams collaborate in online learning tasks in a MOOC? International Review of Research in Open and Distributed Learning, 19, 39-55.

Vielma, K., \& Brey, E.M. (2020). Using evaluative data to assess virtual learning experiences for students during COVID-19. Biomedical Engineering Education, https://doi.org/10.1007/s43683-020-00027-8

Whatley, J. (2006). Student teamwork: Developing virtual support for team projects. Interactive Technology and Smart Education, 3, 157-165.

Wilson, L., Ho, S., \& Brookes, R. H. (2018). Student perceptions of teamwork within assessment tasks in undergraduate science degrees. Assessment \& Evaluation in Higher Education, 43(5), 786-799. 
Workman, M., Kahnweiler, W., \& Bommer, W. (2003). The effects of cognitive style and media richness on commitment to telework and virtual teams. Journal of Vocational Behaviour, 63, 199-219.

Yoon, S. W., \& Johnson S. D. (2008). Phases and patterns of group development in virtual learning teams. Educational Technology Research and Development, 56, 595-618.

Zalesny, M. D., Salas, E., \& Prince, C. (1995). Conceptual and measurement issues in coordination: Implications for team behavior and performance. Research in Personnel and Human Resources Management, 13, 81-115. 


\section{Appendix 1}

Information on the demographic composition of virtual teams

\begin{tabular}{|c|c|c|c|c|c|c|c|}
\hline Assn. & Team & Field of study & $\begin{array}{c}\text { Gender } \\
\text { F/M }\end{array}$ & $\begin{array}{c}\text { Enrolment } \\
\text { year }\end{array}$ & $\begin{array}{l}\text { University } \\
\text { affiliation }\end{array}$ & Origin & $n=$ \\
\hline \multirow{5}{*}{ 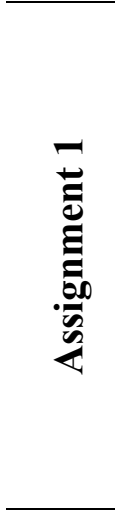 } & $\# 1$ & Int/Area; Lang/Cul. & $\begin{array}{c}\mathrm{F}=3 \\
\mathrm{M}=1\end{array}$ & $1,2,3$ & $\mathrm{~A}$ & $\begin{array}{l}\text { Jap. }=4 \\
\text { Int. }=0\end{array}$ & 4 \\
\hline & $\# 2$ & $\begin{array}{l}\text { Int/Area; Lang/Cul; } \\
\text { Jap. }\end{array}$ & $\begin{array}{l}\mathrm{F}=3 \\
\mathrm{M}=1\end{array}$ & $1,2,3$ & A & $\begin{array}{l}\text { Jap. }=3 \\
\text { Int. }=1\end{array}$ & 4 \\
\hline & \#3 & $\begin{array}{l}\text { Lang/Cul; Bio/life; } \\
\text { Env/Nat. }\end{array}$ & $\begin{array}{l}\mathrm{F}=3 \\
\mathrm{M}=1\end{array}$ & $1,2,3$ & A, B & $\begin{array}{l}\text { Jap. }=4 \\
\text { Int. }=0\end{array}$ & 4 \\
\hline & $\# 4$ & Int/Area; Lang/Cul. & $\begin{array}{l}\mathrm{F}=3 \\
\mathrm{M}=1\end{array}$ & 1,4 & A & $\begin{array}{l}\text { Jap. }=3 \\
\text { Int. }=1\end{array}$ & 4 \\
\hline & $\# 5$ & $\begin{array}{l}\text { Inf/Eng; Env/Nat; } \\
\text { Lang/Cul; Bio/life. }\end{array}$ & $\begin{array}{l}\mathrm{F}=2 \\
\mathrm{M}=2\end{array}$ & $1,2,3$ & $\mathrm{~A}, \mathrm{~B}, \mathrm{C}$ & $\begin{aligned} \text { Jap. } & =3 \\
\text { Int. } & =1\end{aligned}$ & 4 \\
\hline \multirow{5}{*}{ 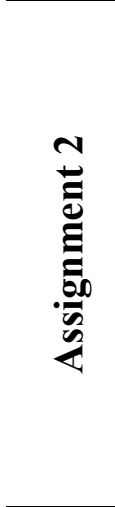 } & $\# 6$ & Int/Area; Lang/Cul. & $\begin{array}{l}\mathrm{F}=3 \\
\mathrm{M}=1\end{array}$ & 1,3 & $\mathrm{~A}$ & $\begin{array}{l}\text { Jap. }=4 \\
\text { Int. }=0\end{array}$ & 4 \\
\hline & $\# 7$ & $\begin{array}{l}\text { Int/Area; Lang/Cul; } \\
\text { Jap. }\end{array}$ & $\begin{array}{l}\mathrm{F}=3 \\
\mathrm{M}=1\end{array}$ & $1,2,3$ & A & $\begin{array}{l}\text { Jap. }=3 \\
\text { Int. }=1\end{array}$ & 4 \\
\hline & \#8 & $\begin{array}{l}\text { Int/Area; Lang/Cul; } \\
\text { Bio/life; Env/Nat; }\end{array}$ & $\begin{array}{l}\mathrm{F}=3 \\
\mathrm{M}=1\end{array}$ & $1,2,3$ & A, B & $\begin{array}{l}\text { Jap. }=3 \\
\text { Int. }=1\end{array}$ & 4 \\
\hline & $\# 9$ & $\begin{array}{l}\text { Env/Nat; Int/Area; } \\
\text { Inf/Eng; Bio/life. }\end{array}$ & $\begin{array}{l}\mathrm{F}=3 \\
\mathrm{M}=1\end{array}$ & $1,2,3$ & $\mathrm{~A}, \mathrm{~B}, \mathrm{C}$ & $\begin{array}{l}\text { Jap. }=4 \\
\text { Int. }=0\end{array}$ & 4 \\
\hline & $\# 10$ & Int/Area; Lang/Cul. & $\begin{array}{l}\mathrm{F}=2 \\
\mathrm{M}=2\end{array}$ & $1,2,4$ & $\mathrm{~A}$ & $\begin{array}{l}\text { Jap. }=3 \\
\text { Int. }=1\end{array}$ & 4 \\
\hline \multirow{5}{*}{ 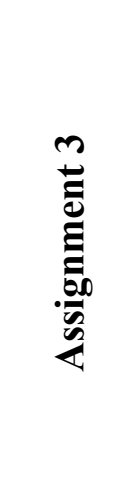 } & \#11 & $\begin{array}{l}\text { Bio/life; Env/Nat; } \\
\text { Lang/Cul. }\end{array}$ & $\begin{array}{l}\mathrm{F}=2 \\
\mathrm{M}=2\end{array}$ & $1,2,3$ & $\mathrm{~A}, \mathrm{~B}, \mathrm{C}$ & $\begin{array}{l}\text { Jap. }=4 \\
\text { Int. }=0\end{array}$ & 4 \\
\hline & \#12 & Int/Area; Lang/Cul. & $\begin{array}{l}\mathrm{F}=3 \\
\mathrm{M}=1\end{array}$ & $1,2,4$ & A & $\begin{array}{l}\text { Jap. }=3 \\
\text { Int. }=1\end{array}$ & 4 \\
\hline & $\# 13$ & $\begin{array}{l}\text { Int/Area; } \\
\text { Lang/Cul; Jap. }\end{array}$ & $\begin{array}{l}\mathrm{F}=3 \\
\mathrm{M}=1\end{array}$ & $1,2,3$ & $\mathrm{~A}$ & $\begin{array}{l}\text { Jap. }=3 \\
\text { Int. }=1\end{array}$ & 4 \\
\hline & $\# 14$ & Inf/Eng; Env/Nat. & $\begin{array}{l}\mathrm{F}=3 \\
\mathrm{M}=1\end{array}$ & $1,2,3$ & $\mathrm{~B}, \mathrm{C}$ & $\begin{array}{l}\text { Jap. }=4 \\
\text { Int. }=0\end{array}$ & 4 \\
\hline & $\# 15$ & $\begin{array}{l}\text { Int/Area; Lang/Cul; } \\
\text { Bio/life. }\end{array}$ & $\begin{array}{l}\mathrm{F}=3 \\
\mathrm{M}=1\end{array}$ & 2,3 & $\mathrm{~A}, \mathrm{C}$ & $\begin{array}{l}\text { Jap. }=3 \\
\text { Int. }=1\end{array}$ & 4 \\
\hline
\end{tabular}

Key: Int/Area = International and Areas studies; Lang/Cul = Language and Culture studies; Jap = Japanese studies; Inf/Eng = Informatics and Engineering; Bio/Life = Biotechnology and Life sciences; Env/Nat = Environmental and natural resources sciences; Assn. = assignment; $\mathrm{F}=$ female; $\mathrm{M}=$ male; Jap. = Japanese students; Int. = International students; $n=$ number of students in each team. 


\section{Appendix 2}

\section{Outline of virtual team assignments}

\begin{tabular}{|c|c|c|c|}
\hline $\begin{array}{l}\text { Task number } \\
\text { (name) }\end{array}$ & Task description \& learning objective & $\begin{array}{c}\text { Allotted } \\
\text { In-class time }\end{array}$ & $\begin{array}{l}\text { Format of } \\
\text { presentation }\end{array}$ \\
\hline $\begin{array}{l}\# 1 \\
(\mathrm{SeeNN})\end{array}$ & $\begin{array}{l}\text { Virtual teams browse through the headlines } \\
\text { and stories of the major news outlets (BBC, } \\
\text { Aljazeera, NHK, CNN, etc.) and search for } \\
\text { real-life manifestations of abstract } \\
\text { concepts, such as 'national interests', } \\
\text { 'international competition', 'international } \\
\text { cooperation', and 'international } \\
\text { organisations'. Teams should decide on } \\
\text { one notable story and make a presentation. } \\
\text { The activity aims to develop students' data } \\
\text { collection, research, analytic, presentation, } \\
\text { and collaborative skills. }\end{array}$ & $\begin{array}{l}2 \text { modules } \\
\text { (180 min) }\end{array}$ & $\begin{array}{l}\text { Debates } \\
\text { and/or Role } \\
\text { play }\end{array}$ \\
\hline $\begin{array}{l}\# 2 \\
\text { (SWOT } \\
\text { Showcase) }\end{array}$ & $\begin{array}{l}\text { Virtual teams are assigned one chapter of } \\
\text { the Routledge Handbook of Japanese } \\
\text { Foreign Policy (2018) on a specific topic }\end{array}$ & $\begin{array}{l}3 \text { modules } \\
(270 \mathrm{~min})\end{array}$ & $\begin{array}{l}\text { Non- } \\
\text { conventiona } \\
\text { presentation }\end{array}$ \\
\hline
\end{tabular}
(climate change, trade, etc.). All members read their chapter and based on its key suggestions develop their original SWOT (Strength - Weaknesses - Opportunities Threats) plan for real-life implementation. Students find a creative way to present their plan. Students practice their textual analysis, problem-solving, communication and collaboration skills.

\begin{tabular}{ll}
\hline$\# 3$ & Virtual teams simulate the process of \\
(Create \& & creating an international organization. The \\
present your & structure and activities of an imaginary \\
original & organization must be consistent with the \\
international & key concepts covered in the course \\
organization) & lectures, including 'Membership', \\
& 'Obligations', \\
& 'Enforcement', 'Sovereignty and Consent'. \\
& Teams are free to choose their own \\
& problem area and title for their \\
& organization. A real-life demonstration of \\
& one of its committee/general assembly \\
& meetings is required. The task aims at \\
& evaluating students' knowledge of \\
& concepts, and help them to practice the \\
& skills of problem-solving, negotiation, \\
& decision making, and communication.
\end{tabular}

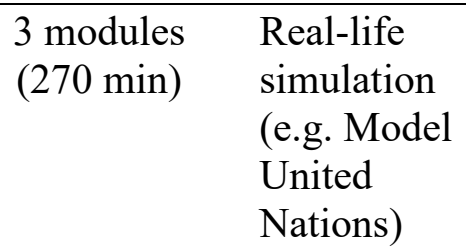




\section{Appendix 3}

\section{Guide to completing virtual teamwork e-portfolios}

- Please carefully go through the list of questions below. Select any question that is related to the most memorable and relevant situation that you observed when working with your virtual team during the last activity. Write a comment in your e-portfolio, which can be accessed by the whole class in 'view only' mode.

- Each e-portfolio comment or observation should be written (in 150 words or more) in a reflective, non-judgemental style with concrete examples of learning experiences and processes. This e-portfolio is part of your course work, however, please keep in mind that your comments and remarks will NOT be judged or assessed in any way. Please, do not mention any names of your virtual teammates (just say "one of my teammates", etc.).

1. MISSION OF YOUR TEAM: You can write about whether you took part in defining the main goal of your team; whether you helped your team to understand the rules and plan the assignment steps smoothly; and whether you understood what you personally should do to help your team.

2. PROBLEM-SOLVING AND STRATEGY OF YOUR TEAM: You can write about whether you helped your team to define its main problems and suggested some solutions or ideas; whether you carefully listened to and supported your other teammates' suggestions to solve the team's problem.

3. OBSERVATIONS: You can write about whether you were carefully observing if the team was making what it had planned to; whether you were carefully observing every teammate's contribution; whether you understood what you should do to make your team's project a success.

4. ENGAGEMENT: You can write about whether you were talking a lot and were trying to give your verbal feedback occasionally; or whether you really wanted (and did so) to help your teammates who were trying to complete their part; and whether you were happy (and did so) to offer your help, when one of your classmates could not handle some task.

5. LEADERSHIP AND COORDINATION: You can write about whether you were comfortable to collaborate with everyone actively many times; whether you were comfortable when your team decided to do something that you did not like very much; whether you tried to play a role of a coordinator (or someone like a team leader).

6. CONFLICT MANAGEMENT: You can write about whether you tried to focus on your common goals (not differences) and you were very positive or discouraged during the assignment; whether you or someone had any communication problem during the team assignment, and you could quickly fix it; whether your team had a conflict of interests, and you would be happy to fix it in a smooth way.

7. MOTIVATION: You can write about whether you tried to keep your confidence level high during the project (you joked, smiled, stayed positive); whether you openly praised your teammate(s) if they did something great or solved a problem; whether you thought you were full of energy and were very excited about your upcoming success.

8. EMOTIONS: You can write about whether you were in full control of your emotions and temper; whether you even if something bad happened, you would have stayed cool without getting emotionally disturbed; whether you always tried to hide emotions that make other people uncomfortable (for example, suddenly screaming or something too funny and little crazy).

Feel free to add anything that is relevant to your virtual teamwork experience. 